\title{
Globalization \\ and Shifting Economic Centers of Gravity
}

\section{By \\ Yener Kandogan}

Changes in the political economy of countries in several parts of the world changed its economic balance, where traditional economic centers lost their relative significance and emerging countries gained. This study identifies and tracts the changes in economic centers of gravity for each country and regional economic bloc, and the whole world for the period of 1970 to 2009. It uses a different methodology and significantly higher number of locations, resulting in more reasonable centers than the previous research. The results demonstrate the increasing significance of Asian economies and illustrate the changes in the soft economic power across regions and the world, in countries' ability to increase their multinationals' market access, influence international policies, and be an attraction for skilled immigrants. Further, results can be used by multinationals for their location decisions. Results also suggest that the economic centers of gravity for countries in an economic bloc are moving toward the regional centers for that bloc. (0) 2014 Wiley Periodicals, Inc.

\section{Introduction}

$\mathrm{T}$ he world's economic sphere has experienced significant changes in the past 40 years. The economies of the formerly socialist countries in central and eastern Europe, including Russia, underwent significant market reforms such as deregulation, privatization, and reinstatement of property rights toward establishing functioning market economies. Changes in the political economy of several countries in Latin America moved them away from decades of populist economic policies. The Southeast Asian countries opened up and followed aggressive exporting promoting economic policies. China, while remaining as politically a communist country, carried out similar market reforms, albeit not as swiftly as central and eastern Europe. As a result, these countries quickly integrated themselves in the new world economic system, taking advantage of globalization of the production and the markets and experienced significant economic growth. All these changes in economic systems in several corners of the world changed the economic balance of the world. While continuing to grow, the 
traditional economic powerhouses in North America and western Europe lost their relative significance. Cox (2007) refers to this as the relative decline of the world's established global powers. However, countries in Asia emerged as new economic powers (Mahbubani, 2008). Further, the rise of the BRICs was noted by the Goldman Sachs Global Economics Group (2007), who gave this acronym to the fast-growing economies of Brazil, Russia, India, and China.

This study attempts to quantify these changes by measuring the economic centers of gravity and tracking their location as certain countries or regions lose their relative significance and others gain throughout time. These new or emerging centers will have important policy implications as the world economies integrate and become interdependent; rather than military power, the soft power of countries resulting from their economy will give these emerging centers significant influence in world affairs, as described in the next section. Further, this study has other practical implications such as guidance to multinationals with regard to parts of the world they need to consider as part of their expansion plans, as emerging markets and even potential locations for their operations.

A few other studies have previously estimated this same concept of world economic center of gravity, focusing only on a few large urban agglomerations (Grether \& Mathys, 2009). Later, Quah (2011) built on their idea by adding observations to cover all of the world's economies, particularly considering rural economic activity located outside urban agglomerations. He used 483 large urban locations in 210 countries and augmented his data by producing one rural proxy for each country. The projected longitude and latitude of the center identified in Quah (2011) for 2008 corresponds to Mersa Matruh, a Mediterranean seaside town in the north of Egypt. This seems fairly contrary to most people's expectations, as does his projection for 2049: Lhasa in Central China just north of Bhutan. Despite losing relative significance-the North American and West European economies' size-one would still expect that the world economic center would be located between North American and European continents shifting north toward Asia due to their emerging economies. These raise questions about validity of the methodology in Quah (2011).

In this analysis, rather than rural proxies, I included any agglomeration that constitutes at least $1 \%$ of a country's population, thus increasing the number of locations to include not only large urban cities but also small- or medium-scale rural agglomerations, totaling

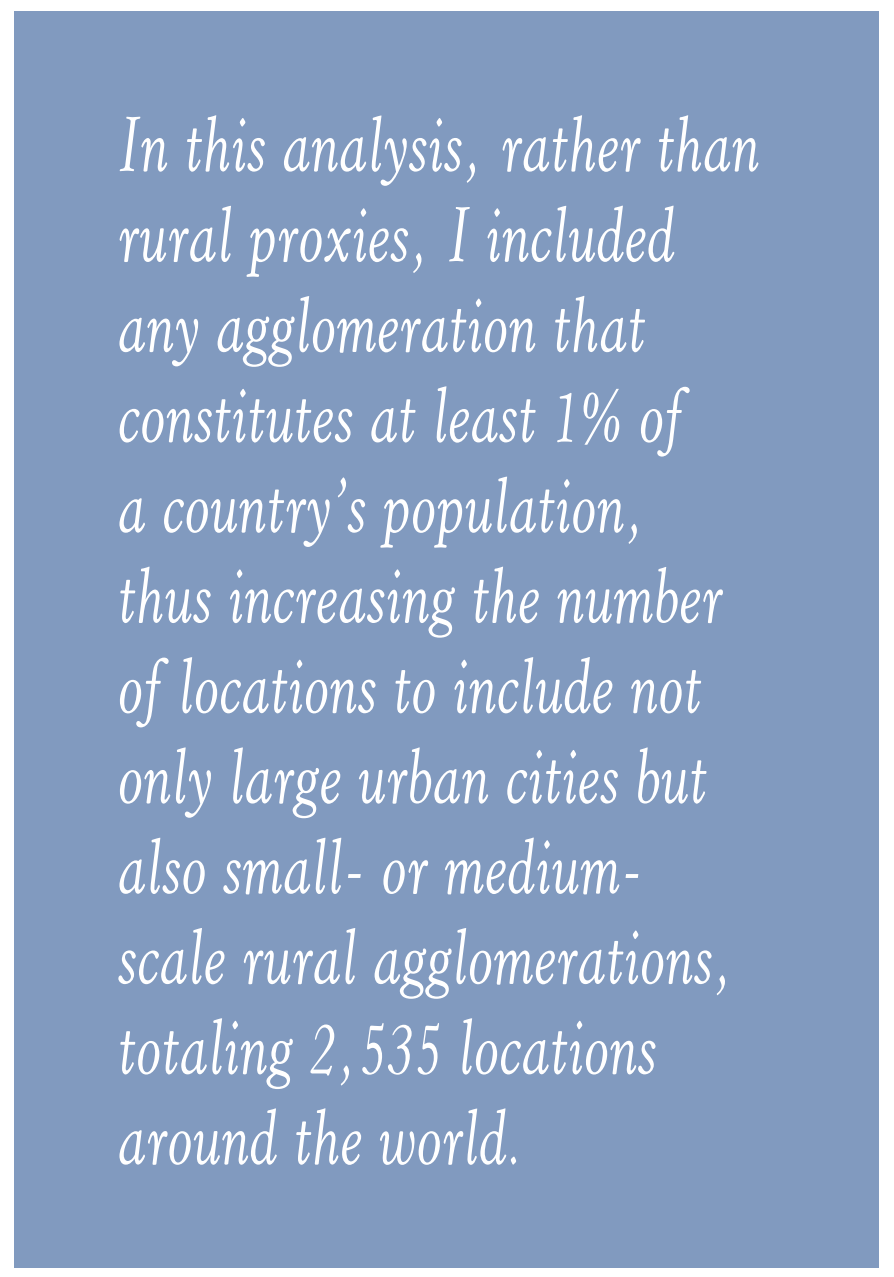

2,535 locations around the world. While I computed the world's economic center of gravity out of curiosity and for comparison with Quah's (2011) study, this center has little practical implications. Therefore, the emphasis in this study has been the location of and the shifts in the economic centers for a country or for a region defined by economic integration agreements, which was not done in previous studies.

\section{Soft Power}

Soft power represents countries' ability to attract and co-opt by using nonmilitary force as a means of persuasion (Nye, 2004). Mattern (2005) argues that it indirectly allows a country to obtain the outcomes it wants. Soft power can be used for resolution of international conflicts, opening of markets for its industries, and shaping the environment for policy such as international trade negotiations, international law, policies of international organizations such as International Monetary 
Fund, World Bank, and World Trade Organization. Nye (2004) identifies values, culture, policies, and institutions as the primary currencies of soft power. As countries gain more soft power, their values and culture will be more attractive, and their policies and institutions will influence those of other countries. People in other countries will try to learn the language of countries with soft power, as they will be become more and more significant in international business communications. Further, overall appeal of these countries to potential skilled immigrants will increase leading to significant advantage in terms of technology and innovation the countries with soft power.

The literature points out to the significance of these consequences of soft power, increased market access, increased influence on international policies, influential language/culture, and attraction for skilled immigrants for success in international business. Hitt, Hoskisson, and Kim (1997) and Tallman and Li (1996) provide evidence that international expansion achieved through greater market access is linked to greater firm profitability. Woods and Lombardi (2006) assert that powerful countries are cast as the principals of international organizations, such as the International Monetary Fund (IMF), whether in the executive boards or in the senior management, thus influence their policies. Lazear (1999) argues that cultural intermediaries that are cross-culturally literate, and speak multiple languages increase trade between countries by reducing costs associated with mistrust, difficulties in communication and misunderstandings. Finally, immigrants increase exports performance by reducing transactions costs and their facilitating role in deterring opportunism (Globerman, 1995; Rauch \& Trindade, 2002; Wagner, Head, \& Ries, 2002).

Anecdotal evidence points to increasing Chinese soft power. An example of this comes from its impression on African countries. Survey data shows that Africans view China as a positive influence for their country. China's substantial economic growth over the years and its increase in trade and investment in African countries leads to this positive impression about China in these countries.

Institute for Government and Monocle measures soft power through a composite index, where two key variables are population size and gross domestic product. Hence, tracking the shifts regional economic centers of gravity through a methodology that is heavily influenced by these factors, as described in the next section, can help identifying countries gaining more soft power, and becoming more influential.

\section{Data and Methodology}

In physics, the center of gravity summarizes the gravitational forces. It is characterized as the point about which there is no torque, defined as the tendency of a force to rotate an object. It is computed as the weighted average of the locations of the particles composing the object:

$$
\bar{r}(\bar{x}, \bar{y}, \bar{z})=\frac{1}{W} \sum_{i} w_{i} * r_{i}\left(x_{i}, y_{i}, z_{i}\right)
$$

where $w_{i}$ is the scalar weight of particle $i$ and $r_{i}$ vector representing the location of the particle in three-dimensional Cartesian coordinates. $W$ is the cumulative weight of all of the particles.

Application of gravity concepts from physics into international business, particularly in predicting international trade and investment flows, has long been done quite successfully. Numerous previous studies (Deardorff, 1984; Eichengreen \& Irwin, 1998; Evenett \& Keller, 2002; Feenstra, 1998) have shown that the most fruitful way to predict international trade flows is through gravity-type models. Given its empirical success in predicting trade flows, gravity models have also been used extensively in predicting the pattern of foreign direct investment (Guerin, 2006; Lane \& Milesi-Ferretti, 2008). In these articles, the gravitational forces are modeled using the gross domestic product (GDP) of the countries. In this study, I take a similar approach and use the GDP. In particular, applying Equation (1) to compute the economic center of gravity of a country, the country will be the object, the administrative units within the country will be the particles, and the scalar weights will be the GDP generated in each of these units. The location of the central cities in each administrative unit is used as vector in the equation. Similarly, in computing the center of gravity of a region, the object will be the region, and the particles will be the countries in that region. Each country will affect the location of the regional economic center of gravity proportionally to their GDP, and vectors representing the locations of countries will be at their own economic center of gravity.

Country-level GDP data are obtained from the United Nations National Accounts Main Aggregates Database. Units of measurement are current US dollars. GDP in each administrative unit in a country is computed by multiplying a country's GDP with the share of the unit in the overall population of the country. While it is clearly an approximation, per-capita GDPs across administrative units in a country are assumed to be the same. The assumption is supported under perfect labor mobility within a country, where the population will flow in or 
out of each of these administrative units closely following the differences in per-capita GDPs, and eventually equalizing these across units. Labor mobility assumption is reasonable for almost all countries of the world and is needed in the absence of GDP or per-capita GDP data from each administrative unit in all countries studied that would have allowed for taking into account such unitwide variation. In cases of countries with severe income imbalances, this assumption would make cities with lower incomes more significant, biasing these countries' economic center toward such cities. Several other studies also used population changes within a country as an instrument to track down changes in economic activity in their analyses (Ades \& Glaeser, 1995; Henderson, 2003; Junius, 1999; Moomaw \& Shatter, 1996; Nitsch, 2006). The same per-capita GDP was also assumed in Grether and Mathys (2009) and Quah (2011) for large urban locations.

The population data provided by Brinkhoff (n.d.) is a collection of data from official censuses. The dataset covers the period of 1970 to 2009 for 165 countries, omitting only tiny island countries in the Caribbean and the Pacific. A few relatively larger countries had also to be eliminated due to lack of other data used in the analysis such as location coordinates and/or GDP. The list of countries included is provided in Table 1. Censuses were not carried out on an annual basis but periodically. While most censuses were done every five years, this frequency also changes from one country to another. Hence, I estimated the annual population figures in between two censuses by assuming constant percentage rate of growth or decline. Rather than the population of individual cities, that of administrative units is monitored. These include a central city or cities and neighboring nonurban towns/suburbs forming a connected region of dense and economically linked administrative unit. Only units representing at least $1 \%$ of the overall country population, a total of 2,535, are included in the analysis for simplicity.

Data on the locations of these administrative units is obtained from World City Latitude Longitude Database. The data obtained are in radians. For each administrative unit, they are converted into three-dimensional Cartesian coordinates as follows:

$$
\begin{aligned}
& x_{i}=\cos \left(\text { long }_{._{i}}\right) * \cos \left(\text { lat }_{._{i}}\right) \\
& y_{i}=\sin \left(\text { long. }_{._{i}}\right) * \cos \left(\text { lat }_{i_{i}}\right) \\
& z_{i}=\sin \left(\text { lat }_{i}\right)
\end{aligned}
$$

where lat $_{i}$ and long. ${ }_{i}$ are latitude and longitude of administrative unit $i$, respectively. Note that the center of the Earth will have zero for all of these coordinates. The above converts each location to Cartesian coordinates with a maximum height of 1 , which corresponds to the surface of the Earth. As discussed earlier, these are weighted with each unit's GDP, and scaled using the cumulative weight, which is the GDP of the country at time $t$ to compute the location of its economic center of gravity as follows:

$$
\begin{aligned}
\overline{\mathrm{x}}_{t} & =\sum_{i} \operatorname{gdp}_{i t} * x_{i} / \mathrm{GDP}_{t} \\
\bar{y}_{t} & =\sum_{i} \operatorname{gdp}_{i t} * y_{i} / \mathrm{GDP}_{t} \\
\overline{\mathrm{z}}_{t} & =\sum_{i} \operatorname{gdp}_{i t} * z_{i} / \mathrm{GDP}_{t}
\end{aligned}
$$

Note that the Cartesian coordinates of the economic center of gravity will again have a maximum height of 1 . Hence, the economic center of gravity will be inside the Earth.

Cartesian coordinates of the economic center of gravity are then converted back to latitude and longitude in degrees using:

$$
\begin{aligned}
& \overline{\text { lat. }}=\operatorname{asin}(\bar{z}) * \frac{180}{\pi} \\
& \overline{\text { lat. }}=\operatorname{atan} 2(\bar{x}, \bar{y}) * \frac{180}{\pi}
\end{aligned}
$$

Note that if the formula from physics were directly applied to compute the center of gravity, it would have produced a center inside the Earth. This would not have made practical sense because trade routes would never go through the Earth. This process solves this practical issue by producing the projection of the economic centers of gravity inside the Earth to a corresponding point on the surface following a ray from the center to the surface passing through this point inside, as illustrated in Figure 1. This process computes latitudes and longitudes of the center on the surface of the Earth. The function atan2 in Equation (4) returns the arctangent of the specified $x$ and $y$ coordinates in radians between $-\pi$ and $\pi$. This is identical to arctangent of the ratio of $y$ to $x$, but in this function $x$ can be equal to 0 , which is possible in this application.

Once countries' economic centers of gravity are computed using the methodology described above, I compute the regional centers using each country as a particle in Equation (1), with a vector of their location at the computed centers of gravity and a scalar weight equal to their GDP. Countries are grouped into regions primarily based on their regional economic integration agreements and proximity to these regions in the absence of any agreement or multiples of agreements. These are provided in Table 1. For example, while all countries listed have agreements with the European Union (EU), they are grouped into West and East Europe regions based on their proximity to these structurally different 
TABLE 1 Economic Blocs of the World

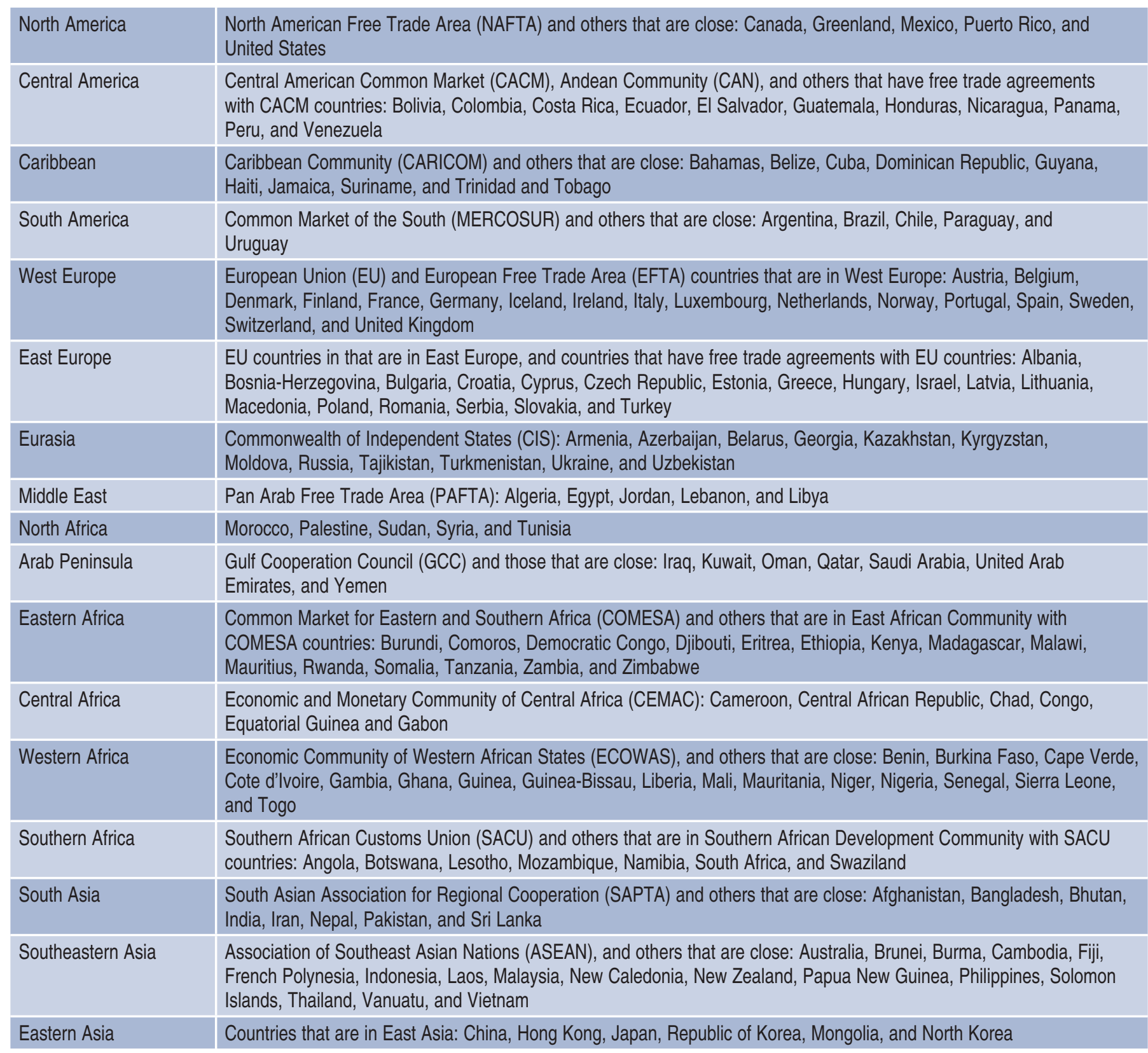

regions. These include not only countries that are EU members, but also those that have free trade agreements or are potential candidates for EU membership in the future. Israel is included in East Europe, due to its free trade agreement with the EU, its proximity to Turkey and Cyprus in East Europe, and its lack of economic integration with other countries in the Middle East region.

In computing the distances between the economic centers of gravity throughout the period of analysis, the Haversine formula is used. This yields the great-circle distance between two points, which is the shortest distance over the Earth's surface "as the crow flies."

The methodology described above is expected to produce superior results than those of previous studies. Grether and Mathys (2009) use only cities with population larger than 1 million, producing only 392 cities. Quah (2011) updates the list of such large urban agglomerations to increase it to 483 cities, and also added one location per country to represent nonurban locations, adding another 210 locations. To compute the 
FIGURE 1 Computing the Center of Gravity in Three Dimensions

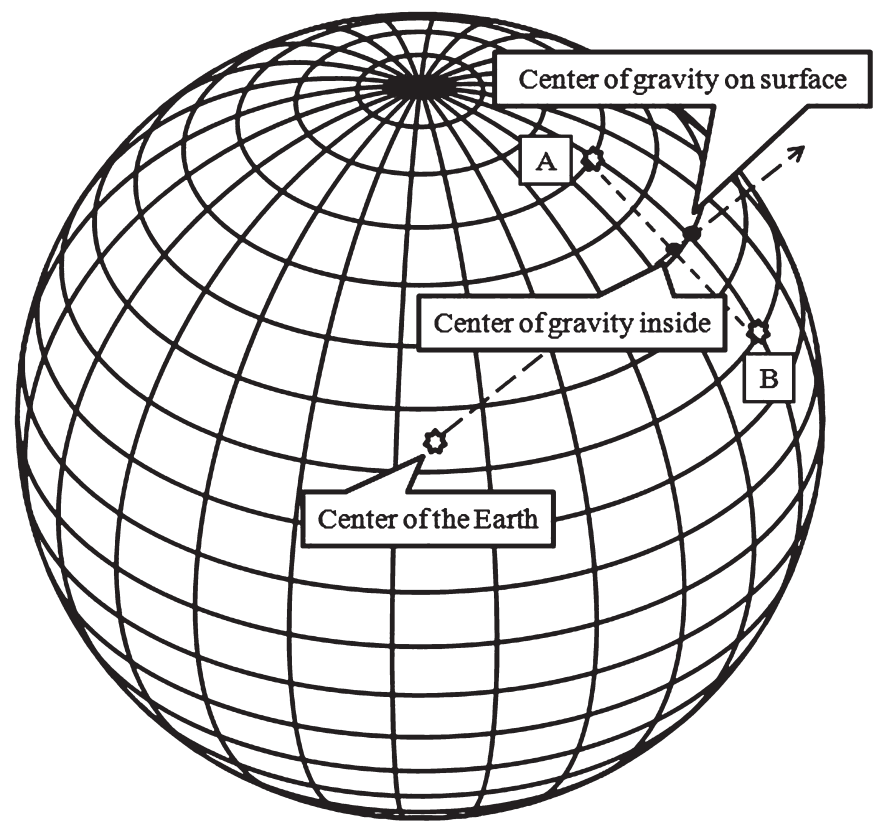

only nonurban location for each country, he uses uniform spatial averaging across the country's geography, which assumes the population is uniformly distributed across the country. Both studies assume the same income levels across large urban locations. Quah (2011) assumes $10 \%$ lower per-capita income for the nonurban location identified for each country. Rather than using a flat 1 million population limit for locations to be considered in the analysis, this study includes all locations-large, medium, or small-where at least $1 \%$ of the population resides. This produces a significantly higher number of locations $(2,535)$ to be considered in computations of the economic center of gravity. With more data points, this approach is expected to produce more reliable results, as each country is taken into consideration, whether or not they have a city with a population over 1 million. Several countries do not and were ignored in previous studies. Quah (2011) attempts to include medium and small cities by adding one nonurban center for each country, but the location of that center is computed assuming the same population density across the geography of the country. This study makes no such assumptions and considers small and medium-scale locations where they actually are.

\section{Empirical Results}

The preceding methodology is applied to all 165 countries to locate their economic centers of gravity. Table 2
It appears that the economic centers of gravity of individual countries in a region are moving toward the regional centers.

lists those centers for the world's largest economies in G20 and the location of the nearest large city in 1970 and 2009, the start and the end of the period of analysis, respectively. Accordingly, while the economic center of gravity for the United States was somewhere around St. Louis in 1970, it moved west and slightly south closer to Kansas City. The table also gives the projections for the future if the trend in the direction continues, which makes Oklahoma City the future economic center of gravity for the United States. The direction of the center's move is similar in Canada. In Mexico, the other major economy in North America, the center moved north. It appears that the economic centers of gravity of individual countries in a region are moving toward the regional centers. The direction of movement for the world's second-largest economy, China, was east toward Japan, moving from near Xiangyang in 1970 closer to Suizhou in 2009, heading toward Nanjing farther east. Similarly, the center for Germany moved southwest from Eisenach to Fulda, heading in the direction of Frankfurt, and the center for the United Kingdom is moving southeast toward Northampton. While there are a few exceptions to this observation, similar patterns are observed in other regions, as illustrated by the move to the northwest for India, and north for Australia and South Africa.

In Southeast Asia, it looks like the developed countries of Australia and New Zealand in the southern portion of this region are losing relative significance as the center is moving northwest toward developing countries in this region. The center was in the Northern Territory in Australia in 1970s, which moved 907 kilometers to the most northern corner of Western Territory in Australia in 2009. It looks like the economic center of gravity is heading toward the eastern islands of Indonesia. Consequently, larger cities in these islands, such as Surabaya, Denpasar, or Tanete, are gaining significance. When 
table 2 Economic Center of Gravity of G20 Countries

\begin{tabular}{|c|c|c|c|}
\hline Country & 1970 Center of Gravity (Nearest City) & 2009 Center of Gravity (Nearest City) & Future Center \\
\hline United States & $38^{\circ} 52^{\prime} \mathrm{N} 90^{\circ} 50^{\prime} \mathrm{W}$ (St. Louis) & $38^{\circ} 10^{\prime} \mathrm{N} 93^{\circ} 31^{\prime} \mathrm{W}$ (Kansas City) & Oklahoma City \\
\hline China & $32^{\circ} 41^{\prime} \mathrm{N} 112^{\circ} 38^{\prime} \mathrm{E}$ (Xiangyang) & $32^{\circ} 45^{\prime} \mathrm{N} 113^{\circ} 29^{\prime} \mathrm{E}$ (Suizhou) & Nanjing \\
\hline Japan & $35^{\circ} 47^{\prime} \mathrm{N} 137^{\circ} 4^{\prime} \mathrm{E}$ (Gujo) & $35^{\circ} 43^{\prime} \mathrm{N} 137^{\circ} 15^{\prime} \mathrm{E}$ (Gero) & Nakatsugawa \\
\hline Germany & $50^{\circ} 53^{\prime} \mathrm{N} 9^{\circ} 58^{\prime} \mathrm{E}$ (Eisenach) & $50^{\circ} 41^{\prime} \mathrm{N} 9^{\circ} 41^{\prime} \mathrm{E}$ (Fulda) & Frankfurt \\
\hline France & $47^{\circ} 23^{\prime} \mathrm{N} 2^{\circ} 40^{\prime} \mathrm{E}$ (Le Noyer) & $47^{\circ} 14^{\prime} \mathrm{N} 2^{\circ} 38^{\prime} \mathrm{E}$ (Hunbligny) & Bourges \\
\hline United Kingdom & $52^{\circ} 30^{\prime} \mathrm{N} 1^{\circ} 10^{\prime} \mathrm{W}$ (Gilmorton) & $52^{\circ} 22^{\prime} \mathrm{N} 1^{\circ} 2^{\prime} \mathrm{W}$ (Guilsborough) & Northampton \\
\hline Brazil & $18^{\circ} 2^{\prime} \mathrm{S} 44^{\circ} 5^{\prime} \mathrm{W}$ (Diamantina) & $17^{\circ} 31^{\prime} \mathrm{S} 44^{\circ} 25^{\prime} \mathrm{W}$ (Pirapora) & Brasilia \\
\hline Italy & $42^{\circ} 58^{\prime} \mathrm{N} 11^{\circ} 59^{\prime} \mathrm{E}$ (Po Bandino) & $42^{\circ} 55^{\prime} \mathrm{N} 12^{\circ} 5^{\prime} \mathrm{E}$ (Montegabbione) & Terni \\
\hline India & $22^{\circ} 3^{\prime} \mathrm{N} 80^{\circ} 16^{\prime} \mathrm{E}$ (Baihar) & $22^{\circ} 11^{\prime} \mathrm{N} 79^{\circ} 58^{\prime} \mathrm{E}$ (Seoni) & Jabalpur \\
\hline Canada & $48^{\circ} 6^{\prime} \mathrm{N} 83^{\circ} 19^{\prime} \mathrm{W}$ (Timmins) & $48^{\circ} 16^{\prime} \mathrm{N} 86^{\circ} 0^{\prime} \mathrm{W}$ (Thunder Bay) & Winnipeg \\
\hline Russia & $56^{\circ} 32^{\prime} \mathrm{N} 46^{\circ} 33^{\prime} \mathrm{E}$ (Kozmodemyansk) & $56^{\circ} 16^{\prime} \mathrm{N} 46^{\circ} 5^{\prime} \mathrm{E}$ (Kozmodemyansk) & Nizhny Novgorod \\
\hline Australia & $34^{\circ} 33^{\prime} \mathrm{S} 145^{\circ} 30^{\prime} \mathrm{E}$ (Coleambally) & $34^{\circ} 9^{\prime} \mathrm{S} 145^{\circ} 34^{\prime} \mathrm{E}$ (Griffith) & Griffith \\
\hline Mexico & $21^{\circ} 1^{\prime} \mathrm{N} 100^{\circ} 13^{\prime} \mathrm{W}$ (El Capulin) & $21^{\circ} 11^{\prime} \mathrm{N} 100^{\circ} \mathrm{g}^{\prime} \mathrm{W}$ (Victoria) & San Luis Potosi \\
\hline Republic of Korea & $36^{\circ} 16^{\prime} \mathrm{N} 127^{\circ} 37^{\prime} \mathrm{E}$ (Daejeon) & $36^{\circ} 44^{\prime} \mathrm{N} 127^{\circ} 26^{\prime} \mathrm{E}$ (Cheongju) & Yongin \\
\hline Turkey & $39^{\circ} 43^{\prime} \mathrm{N} 31^{\circ} 30^{\prime} \mathrm{E}$ (Sivrihisar) & $39^{\circ} 41^{\prime} \mathrm{N} 31^{\circ} 32^{\prime} \mathrm{E}$ (Sivrihisar) & Sivrihisar \\
\hline Indonesia & $5^{\circ} 26^{\prime} \mathrm{S} 109^{\circ} 54^{\prime} \mathrm{E}$ (Semarang) & $5^{\circ} 7^{\prime} \mathrm{S} 109^{\circ} 34^{\prime} \mathrm{E}$ (Semarang) & Riau Silip \\
\hline Saudi Arabia & $23^{\circ} 21^{\prime} \mathrm{N} 43^{\circ} 26^{\prime} \mathrm{E}$ (Mahazat As-Sayd) & $23^{\circ} 30^{\prime} \mathrm{N} 43^{\circ} 37^{\prime} \mathrm{E}$ (Mahazat As-Sayd) & Riyadh \\
\hline South Africa & $29^{\circ} 34^{\prime} \mathrm{S} 27^{\circ} 19^{\prime} \mathrm{E}$ (Petlane) & $29^{\circ} 9^{\prime} \mathrm{S} 27^{\circ} 15^{\prime} \mathrm{E}$ (Tweespruit) & Welkom \\
\hline Argentina & $32^{\circ} 23^{\prime} \mathrm{S} 61^{\circ} 4^{\prime} \mathrm{W}$ (San Lorenzo) & $32^{\circ} 19^{\prime} \mathrm{S} 61^{\circ} 11^{\prime} \mathrm{W}$ (Gobernador Galvez) & Cordoba \\
\hline
\end{tabular}

the Southeast Asia region is divided into two regions as the Association of Southeast Asian Nations (ASEAN) countries, and Oceania, including all other countries in this region, different cities gain significance. In the ASEAN region, the center in 1970 was in South China Sea near Ho Chi Minh City in Vietnam, moving south for 343 kilometers toward Kepulauan Riau Island near Malaysia. Kuching in Malaysia emerges as an important city if this trend continues. In Oceania, Canberra in Australia seems to be the center both in 1970 and in 2009, moving north only 55 kilometers.

In both South and East Asia regions, the initial trend has been reversed in later decades. In South Asia, the center moved relatively sharply from the Madhya Pradesh region in the direction of northwest, toward other countries in the region, as Iran and Pakistan experienced significant growth in 1970s. In later decades, India gained relative significance, reversing the trend to the southeast. Overall, the center moved northwest 201 kilometers from 1970 to 2009. In the future, large cities in Rajasthan such as Jaipur, Jodhpur, or Ajmer look promising as locations. When Afghanistan and Iran are removed from this region so that only South Asian Preferential Trade Arrangement (SAPTA) countries are considered, the results change significantly. As a result, the center moved 354 kilometers southeast to Jabalpur in 1970 and pretty much remained in the neighborhood of this city in 2009, moving only 25 kilometers toward Nagpur. In East Asia, while the initial movement of the regional center of economic gravity was from Busan in South Korea in the 1970s toward Matsue in Japan, in the 1990s it reversed back in the opposite direction toward China, moving 356 kilometers west from the original location. It appears that in the near future it will be located somewhere in the Shandong region, making larger cities such as Qingdao or Yancheng important locations.

No significant changes were observed in West Europe's and Eurasia's economic centers of gravity. The center has been hovering around Luxembourg and Nancy in France in West Europe throughout the period of analysis, moving only 95 kilometers from the original position. Similarly, Ulyanovsk in Russia seems to be at the center of economic activities in the Commonwealth of Independent States in Eurasia. The distance between the original location and the final location is merely 87 kilometers. In both regions, it seems that while all countries' economy grew, their relative significance within the region has not changed dramatically. 
In contrast, throughout most of the period of analysis until the 1990s, the center of economic gravity in East Europe shifted southeast, toward Turkey and Israel, given their relatively high growth rates in comparison to struggling formerly socialist countries in East Europe. If this trend continued, Istanbul, Turkey, would be an attractive location. However, reforms toward establishing market economies in these countries stopped further shifting of the center to the southeast in the 1990s, and in fact reversed the direction in the 2000s toward the northwest. In 2009, the center for this region was located in the neighborhood of Bucharest, Romania, 233 kilometers southeast of the original location in 1970. While both Turkey and Israel have very strong historical trade relations with Europe, one can argue whether these countries belong to the Middle East region. Removing them from this region changes the centers significantly, given the relative economic size of these countries. The center in 1970 moved significantly northwest to near Miskolc in Hungary, heading southwest toward Szolnok in Hungary in 2009.

The center of gravity for economic activities in North America moved 244 kilometers southwest toward Mexico, given its relatively higher economic growth rate, moving from St. Louis to south of Kansas City in 2009. If this trend continues, Tulsa and Oklahoma City will gain significance. Eliminating the non-North American Free Trade Agreement (NAFTA) countries of Greenland and Puerto Rico from this region hardly changed the results, with the original center in 1970 and the final center in 2009 remaining the same. The economic center of gravity in Central America followed a nearly complete circle, starting and ending close to Bogota, Colombia, only 20 kilometers from the original location. The direction of the center of gravity in the Caribbean region changed a number of times: While it moved from Guantanamo in Cuba toward Port-au-Prince in Haiti in the 1970s, it was back in Guantanamo in 1990. With changes in the economies of the 1990s and 2000s, it moved back to the neighborhood of Port-au-Prince in 2009, just 167 kilometers southeast of the original center in 1970. In contrast, there was a clear direction in the way the economic center of gravity moved in South America. It moved from the border region between Northeast Argentina and Brazil for 769 kilometers, in the northeast direction well into Brazil, reaching Sao Jose do Rio Preto in 2009. If this trend continues, Belo Horizonte or Rio de Janeiro could become a more attractive location. When Chile, which is not a member of the Common Market of the South (MERCOSUR), was removed from this region, the center shifted east both at the beginning and end of the period of analysis, from west of Curitiba in Brazil in 1970 to northeast of Ribeirao Preto in Brazil in 2009, but still moving in the direction of Belo Horizonte if the trend continues.

In Western Africa, the center has been generally moving to the east toward Nigeria, while changes in the region's economy reversed the course temporarily to the west in 1980s. In 2009, the economic center of gravity was in the neighborhood of Parakou in Benin, 146 kilometers east of the original center, but it is quite conceivable that in the near future, large cities in Nigeria, particularly Abuja, will be more attractive. Elimination of Mauritania as the only country that is not a member of the Economic Community Of West African States (ECOWAS) did not change the results significantly, leaving the economic center of this region throughout the period of analysis the same, starting in middle Togo in 1970 ending in Parakou in Benin in 2009. In Central Africa, the center has been moving slowly to the southwest from central Cameroon for 202 kilometers toward Yaoundé, which looks like a promising location as the future center of the region's economy. In Eastern Africa, the center has been moving around Tanzanian cities, starting at Tabora, then to Singida, ending in Arusha in 2009, which is located 374 northeast of Tabora. The direction that the center is moving is northeast toward Kenya, making its eastern seaport of Mombasa a central location for the future economic activity in the region. In the southern Africa region, the economic center of gravity has been moving around the western neighborhoods of Pretoria and Johannesburg in South Africa, moving only 119 kilometers away from the original center in 1970. Excluding the northern countries of Angola and Mozambique, which are not members of the Southern African Customs Union, moves the center of economic gravity of this region further south, near Bloemfontein in South Africa. Results are similar in the sense that over the period of analysis the center does not change much, moving north only 68 kilometers.

The Libyan city Benghazi in North Africa, and the Saudi capital Riyadh in the Arabic Peninsula are significant locations in their respective regions. Growing economies of smaller Arab nations in the Persian Gulf moved the center for the latter region 279 kilometers east toward Bahrain and Qatar, making Saudi cities in the gulf area, particularly Al Hofuf and Dammam, gain importance for future economic activity. When Turkey and Israel are added to the Middle East North Africa group, the centers for this region change significantly. The center moves significantly to the north of the Greek island of Crete in the Aegean Sea near Turkey in 1970, moving east 100 kilometers in 2009. Clearly, these two countries dominate the region, as they experienced significant growth. 
Identifying the world's center of gravity does not have practical implications other than observing the trend in the relative significance of emerging countries and their soft power in world affairs. The location of the world's economic center has been changing. In the 1970s, it was located in the Denmark Strait between Greenland and Iceland, in the neighborhood of Kulusuk, Greenland. This original location was more or less between the two major markets of the time: North America, with a GDP of $\$ 1,127$ billion, and West Europe, with a GDP of $\$ 820$ billion. The location of the actual center reflects the emerging significance of other markets, particularly Asian countries. It is noteworthy that the actual economic center of the world moved towards the East Asian center, between Japan and China. In 2009, the center was located $73^{\circ} 10^{\prime} \mathrm{N} 4^{\circ} 32 \mathrm{~W}$, somewhere close to Svalbard islands in Barents Sea, 1,009 kilometers from the original location. The direction and the distance of this shift is a reflection of the relatively high growth rates countries in Asia experienced in comparison to developed countries in North America and West Europe.

Previous studies computed only the world's economic center of gravity, and did not do so for regions, which have more practical implications. Quah (2011), who built on Grether and Mathys's (2009) work, estimated the world's center for 2008 to be at Mersa Matruh, a Mediterranean seaside town in the north of Egypt, or in the author's own words, "just south of Izmir, Turkey" and "on the same longitude as Minsk and Johannesburg."

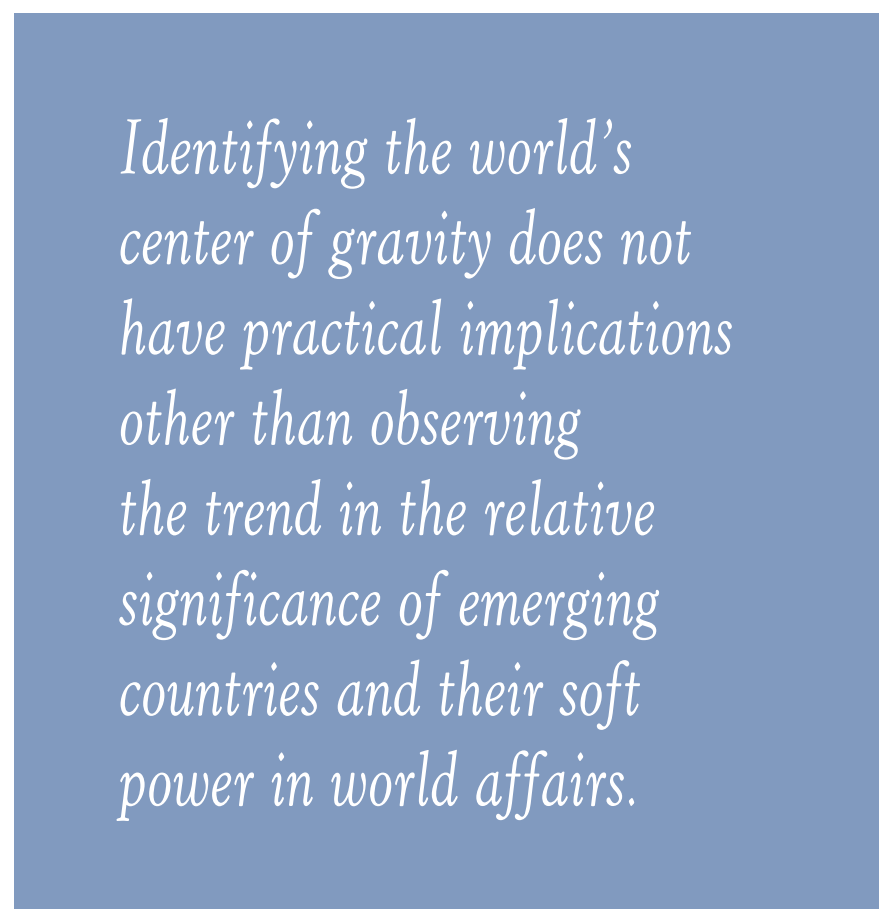

Such a center would require a substantial economic power somewhere in East Africa and South Asia, which are both not economically significant in comparison to North America, Europe, and emerging East Asia. The center computed in this article, which falls somewhere in between these three attractions seems more reasonable. For the same reasons, Quah's (2011) suggestion for the center in 2050-somewhere between Urumqi, China, and Kolkata, India-largely ignores the economic powers to the north: North America, Europe, Japan, and East China. Lack of any significant economic powers to the south makes his prediction for center of economic gravity for 2050 difficult to justify.

\section{Practical Implications}

There are several practical implications of the results of this analysis for policymakers as well as managers in multinational companies. As the soft power of the countries identified increases, policymakers need to take into account the implications of the increased influence of these countries in international organizations such as the World Bank, IMF, and the World Trade Organization (WTO). Their influence over international conflicts can also change the political economy of their regions. Thus, policymakers from the old centers of attraction need to consider getting these new power centers involved in the process to reach to solutions that are viable in the long run.

Managers of multinationals need to take into account the increasing economic significance of emerging centers of economic activity. These locations could guide them as potential markets to consider for expansion, as well as potential locations of operations if tariff rates and other factors in location decisions are favorable. This would be especially important since these emerging locations will be a point of attraction for skilled immigrants. The economic centers for regions could be also considered as potential regional headquarters, as these would be closest to major markets within the region. Multinationals also need to take into account the implications of increased soft power, such as influential language and culture in their decisions, particularly product offerings, marketing approaches, and so on. Strategically hiring employees from these emerging countries or those that are familiar with their cultures and languages would be helpful in this context. At least multinationals should increase their employees' understanding of these countries cultures through training.

In sum, this research identified regional centers to which both policymakers and multinationals should pay closer attention. 


\section{Conclusions}

Tracking the population and gross domestic product changes in more than 2,500 locations in 165 countries, this study identified economic centers of gravity for countries, for regions or economically integrated blocs, and for the whole world, as well as observing their movements for the period of 1970 to 2009. The results support the general sense in the business world that while still important, North America and West Europe are losing their relative significance in comparison to emerging countries in East Europe, Latin America, and particularly East Asia. The methodology used in this article produced an economic center of gravity for the world that seems more consistent with the general expectations than those in previous analyses. This research differs not only in methodology applied and the more extensive data used but also the application of these at country and regional level to provide the multinationals another factor to consider in determining their locations in a country or regional headquarters: proximity to other locations of economic sig- nificance as identified by the economic centers of gravity. Further, the analysis in this paper suggests that countries' economic centers are moving closer to regional economic centers, reflecting regional integration of the economies.

Some of limitations of the study stem from the assumptions made such as use of population to track economic activity in absence of regional economic data and assumption of identical per-capita GDP across regions to proxy regional economic output, considering only locations that constitute at least $1 \%$ of the overall population in a country, and elimination of some countries due to lack of data, and regional groupings of countries. Overall, these assumptions were needed to make this research practical at this extensive level. Future research should certainly look into making reasonable predictions for the future that can consider typical decreases in economic growth rates as countries develop, and consider other factors that affect population growth rates within a country or region, most notably the possibility of labor movements within certain economic blocs.

Yener Kandogan received his PhD in economics from the University of Michigan in 2001. He has taught economics classes at the University of Michigan as well as the University of Notre Dame. He is currently the associate dean of the School of Management at the University of Michigan-Flint, and professor of international business. $\mathrm{He}$ is also a faculty associate at the Center for Russia, East European and Eurasian Studies of the University of Michigan. His research has been primarily on the international trade of East European countries, economic integration, political economy of the European Union, immigration and trade, and role of culture/language on trade. He has 25 publications in peer-reviewed academic journals on international business and international economics. Aside from research interest in intercultural issues, Dr. Kandogan advises international business student organizations in organizing events to support cross-cultural literacy on campus.

\section{References}

Ades, A. F., \& Glaeser, E. L. (1995). Trade and circuses: Explaining urban giants. Quarterly Journal of Economics, 110, 195-227.

Brinkhoff, T. (n.d.). The principal agglomerations of the world. Retrieved from http://citypopulation.de

Cox, M. (2007). Still the American empire. Political Studies Review, 50, $1-10$.

Deardorff, A. (1984). Testing trade theories and predicting trade flows. In R. Jones \& P. Kenen (Eds.), Handbook of international economics (pp. 467-517). Amsterdam, Netherlands: Elsevier Science.

Eichengreen, B., \& Irwin, D. (1998). The role of history in bilateral trade flows. In J. Frankel (Ed.), The regionalization of the world economy. Chicago, IL: University of Chicago Press.

Evenett, S., \& Keller, W. (2002). On theories explaining the success of the gravity equation. Journal of Political Economy, 110, 281-316.
Feenstra, R. (1998). Integration of trade and disintegration of production in the global economy. Journal of Economic Perspectives, 12, 31-50. Globerman, S. (1995). Immigration and trade. In Don De Voretz (Ed.), Diminishing returns: Canada's recent immigration policy. Montreal, Quebec, Canada: C. D. Howe and the Laurier Institution.

Goldman Sachs Global Economics Group. (2007). BRICs and Beyond London, England: Goldman Sachs.

Grether, J. M., \& Mathys, N. (2009). Is the world's economic center of gravity already in Asia? Area, 42, 47-50.

Guerin, S. S. (2006). The role of geography in financial and economic integration: A comparative analysis of foreign direct investment, trade and portfolio investment flows. World Economy, 29, 189-209.

Henderson, J. V. (2003). The urbanization process and economic growth: The so-what question. Journal of Economic Growth, 8, 47-71.

Hitt, M. A., Hoskisson, R. E., \& Kim, H. (1997). International diversification, effects on innovation and firm performance. Academy of Management Journal, 40, 767-798. 
Junius, K. (1999). Primacy and economic development: Bell shaped or parallel growth of cities? Journal of Economic Development, 24, $1-22$.

Lane, P. R., \& Milesi-Ferretti, G. M. (2008). International investment patterns. Review of Economics and Statistics, 90, 538-549.

Lazear, E. (1999). Culture and language. Journal of Political Economy, 107, 95-126.

Mahbubani, K. (2008). The new Asian hemisphere: The irresistible shift of global power to the east. New York, NY: Public Affairs.

Mattern, J. B. (2005). Why "soft power" isn't so soft: Representational force and the sociolinguistic construction of attraction in world politics. Millennium: Journal of International Studies, 33, 583-612.

Moomaw, R. L., \& Shatter, A. M. (1996). Urbanization and economic development: A bias towards large cities? Journal of Urban Economics, $40,13-37$.
Nitsch, V. (2006). Trade openness and urban concentration: New evidence. Journal of Economic Integration, 21, 340-362.

Nye, J. (2004). Soft power: The means to success in world politics. New York, NY: Public Affairs.

Quah, D. (2011). The global economy's shifting center of gravity. Global Policy, 2, 3-9.

Rauch, J., \& Trindade, V. (2002). Ethnic Chinese networks in international trade. Review of Economics and Statistics, 84, 116-130.

Tallman, S., \& Li, J. (1996). Effects of international diversity and product diversity on the performance of multinational firms. Academy of Management Journal, 39, 179-196.

Wagner, D., Head, K., \& Ries, J. (2002). Immigration and the trade of provinces. Scottish Journal of Political Economy, 49, 507-525.

Woods, N., \& Lombardi, D. (2006). Uneven patterns of governance: How developing countries are represented in the IMF. Review of International Political Economy, 13, 480-515. 